\title{
Introduction
}

\author{
Sue Garton and Keith Richards
}

Ten years ago Johnston asked provocatively, 'Do EFL teachers have careers?' The fact that the jury is still out would not surprise him: 'the question', he concluded, 'will have to go unanswered.' (1997: 707). For him, though, it was the wrong question to begin with. Teachers' lives, he argued (Ibid.: 708), 'are lived in complex contexts in which personal, educational, political and socioeconomic discourses all influence the way the life is told'.

The study of such lives, which has a long and respectable pedigree in mainstream educational research, has received only patchy attention in TESOL, though we are now at a point where those whose teaching world was transformed by the communicative revolution are approaching the threshold of retirement. It therefore seems a natural time to examine the sorts of experiences that help shape a working life in our chosen profession, to share understanding and insights among generations, and not least to celebrate what is rich and interesting about our lived world. In that realisation lies the genesis of this book.

Although we will use terms such as 'profession' and 'career', the question of whether TESOL is indeed a profession or even a career is not one that we will consider. In a global context such as ours, the meaning of the question itself varies so much from place to place that the pursuit of any general answer would be fruitless. However, our growing sensitivity to local educational ecologies (Holliday 1994) and rejection of Copernican assumptions about English language teaching (see, for example, Canagarajah 2005; Holliday 2005; Pennycook 1994) does not entail an outright rejection of common experiences in the profession. Prolonged engagement with the many professional worlds of TESOL involves a process of growth and development which fosters the refinement of craft skills, professional knowledge and experiential resources, features of which will be common to most if not all teachers.

Such skills and knowledge are developed through encounters with the professional world and instantiated through talk. Our focus in this book is on the discourses that English language (EL) teachers encounter throughout their careers. We look at the reflexive nexus of discourse, practice and development, at how professional development takes place through professional conversations (Crookes 1997: 68) and is in part defined by these. By analysing the developing discourses of teachers in teaching and training, we aim to shed light on what EL teachers do and why they do it.

The concept of career stages serves as a useful organisational device, but these are interpreted very broadly in terms that will be recognisable to those involved in teaching. Our real interest lies in the discursive encounters of teachers at different points in their careers and what can be learnt from these. TESOL is well served in terms of available training and development courses, both academic and practical, but little attempt seems to have been made to stand back and look at the career trajectory as a whole. Perhaps this is merely because up to now such an attempt would have been premature, but it nevertheless encourages a view of TESOL as a profession temporally as well as geographically compartmentalised.

Our aim, then, is to explore the changes that take place in a teacher's life through some of its constituent discourses. At the same time, we hope to reveal something of the subtle changes in these discourses that take place over the career cycle. 


\section{Organisation of the book}

A full teaching lifetime will see many encounters, some of them wearingly predictable (Doyle 1986, for example, refers to the finding that an average elementary school teacher will publicly praise or blame pupils 16,000 times a year) and others utterly transformative. In this book we have imagined such a lifetime and have tried to trace the teaching world as it might seem from the perspective of a teacher moving through the different stages of the career trajectory.

In order to do this we have taken as our point of orientation Huberman's classic description of the teacher career cycle (Figure 0.1). This is by his own admission an imperfect representation of a complex and varied journey and it is by no means the only description available (for similar work, see Fessler and Christiansen 1992; Sikes, Measor, and Woods 1995), but it nevertheless provides one of the most useful general routemaps available to us.

The basic model will probably be familiar to most teachers on the basis of their own professional experiences and observations, and although it is impossible to reflect the full range of encounters and discoveries that characterise each stage, the chapters that make up this volume address what we believe to be a representative range of issues. We have omitted only the final stage of Huberman's model because professional engagement is a core dynamic of the collection and the issues raised by the process of disengagement fall outside this. Similarly, in Part III we have focused on seeking new horizons rather than reaching a professional plateau, which has been recognised as a distinct stage by some researchers (see Day, Stobart et al. 1996: 174). In taking this view we might be criticised for excessive optimism, but the orientation of all involved in this project is to the possibility of productive engagement.

This leaves four stages, made up as follows:

\section{Part I Starting Out (survival and discovery)}

This section focuses on previous learning experiences, initial teacher training and the classroom experience of the beginning teacher. One of the key elements in any introductory training programme is teaching practice and the feedback on this. The first two chapters focus on this vital area, Copland from the perspective of the trainee and Kurtoglu Hooton on the nature of the feedback itself. Taken together, these two chapters provide important insights that will help those involved maximise the impact of this essential encounter. The other important form of learning, from classroom experience, is addressed by Seedhouse, who uses classroom evidence to highlight some of the important differences between the classroom interaction of novice teachers and that of their more experienced colleagues.

\section{Part II Becoming Experienced (stabilisation)}

The emphasis here is on the sort of experiences and challenges that shape the more established teacher's development. Garton's chapter links the classroom discourse that was the focus of Seedhouse's chapter with teacher beliefs, aiming to raise awareness of the extent to which particular belief systems impact on classroom behaviour. Howard's contribution tackles an aspect of teaching that looms large in teachers' professional world but has been strangely neglected by researchers: the observed lesson. It explores what happens when 
experienced teachers are observed in the classroom for the purposes of appraisal and suggests ways of making the most of this challenging situation. Finally, Morris Adams shifts the focus outside the classroom and explores how teachers can productively engage with the linguistic experiences of their students outside the classroom environment.

\section{Part III New Horizons (experimentation/reassessment)}

Many teachers reach a point in their careers where they feel the need to explore new aspects of their professional world. One way of doing this is through study at Master's level, and this has been the focus of interesting research, some of it from the perspective of discourse development (see, e.g., Cutting 2000; Freeman 1991, 1992). However, there are many other dimensions of exploration which seem to have been neglected. Quirke's chapter is set in the context of a Master's programme but looks at the potential of the web as a medium for sharing professional knowledge and understanding. Mann's chapter stays on the theme of sharing but looks at it from the perspective of developing ideas with fellow teachers through professional talk. Richards's contribution focuses on a situation where a group of teachers were given the rare opportunity to start a school from scratch. It describes the process of establishing the school, relating this to the teachers' aims and the eventual development of distinctive ways of interacting.

\section{Part IV Passing on the Knowledge (serenity/relational distance)}

There are many ways in which teachers might pass on knowledge; in fact, it is something that goes on in small but not insignificant ways in staffrooms around the world. Those who wish to communicate their ideas and understandings to a wider community, however, must look beyond this to the potential of teacher training or publication. Kuchah Kuchah presents the challenges of professional development in sub-Saharan Africa as he explores the teaching/learning culture of power relationships and its discourses during his journey from classroom teacher to one of the youngest school inspectors in Cameroon. Wharton addresses the process of writing for publication, showing what this involves, professionally and discoursally, for teachers who wish to develop their ideas into published works. Finally, in a fitting conclusion to the collection, Edge reflects on 40 years in TESOL, exploring dimensions of evaluative discourse and their developmental potential.

The focus of this book is on practising English language teachers and their concerns at different stages in their professional lives. The selection of topics covered has been informed by a desire to offer insights and illustrations that will allow teachers to rethink aspects of their experiences and opportunities at particular stages in their development, so although the chapters are research-based they are orientated to the practical needs of teachers. Because the voices of teachers are heard only indirectly, and usually within an analytical framework which may act as a selectional and interpretive filter, we felt it was also important to hear the voice of the teacher directly.

Each of the four parts is therefore not only preceded by an introduction setting the chapters in their conceptual context, but also followed by a reflection from a practising teacher at that stage in his or her career. The teachers, chosen to represent not only different career stages but also different cultural and experiential settings, were invited to read and comment from their own perspectives on the chapters in their section. They were given the following points as a guide to follow, if they wished: 
- Where am I now? What am I doing? Where • have I come from andwhere am I going?

- What matters to me now? What are the issues that concern me?

- How far do these chapters address these issues? What's most important about them?

- What's missing? What lessons can I pass on, if any?

- If I had one message to pass on to someone approaching this phase in their career cycle, what would it be?

To ensure that the teachers' voices are authentic, no editorial control was exercised over their contributions, which have been left exactly as they were written, save minor corrections to typing errors. Considered along with the issues raised in the introductory section, the resulting observations should serve as a useful starting point for reflection and discussion. Inevitably, much of this will be from the perspective of a particular career stage, but the presence of views from different stages also offers the possibility of broader contextualisation in terms of the career trajectory as a whole and the unfolding relationship between knowledge, discourse and action.

\section{The career trajectory}

Globally, English language teaching is worth billions of pounds and it depends - even in a world saturated comprehensively with communications technology - on the daily efforts of the teachers whose knowledge and experience, gathered through a lifetime of professional development, contribute immeasurably to its success. Yet, despite the huge literature generated to serve the interests of the field, until recently the teacher remained an almost invisible figure, an assumed constant in a history marked by dramatic changes of approach and orientation. Huberman perfectly captures the resulting distortion of perspective:

When one overlooks people's lives to focus on events ... or on the institutional theatres of those events, one is taking the actors out of the play and assuming that the scenery is animate enough to carry the plot and account for the denoument.

(Huberman 1988: 120)

The consequences of this have perhaps not been fully appreciated. Books designed for teachers, such as those focusing on methods, materials or professional development, have traditionally adopted what might be described as an all-life approach, which ignores the changing perspectives that characterise a teaching life. The new teacher struggling to master the essential skills of day-to-day planning, preparing, teaching and staffroom socialising will not respond to new ideas or fresh initiatives in the same way as an experienced colleague. Over time, perspectives shift as contexts and colleagues change, skills are refined, knowledge develops and views mature. Although it is clearly neither feasible nor necessary (since teachers are more than capable of assessing the relevance or otherwise of a piece of advice in terms of their own professional circumstances) to organise books for teachers in terms of career stages, there is nevertheless a need for greater recognition of the importance of this aspect. This collection offers an approach that, by highlighting key encounters at each stage in the career trajectory, maximises the potential for knowledge growth and development at that stage.

It has been argued that TESOL is a 'permeable' profession (Maley 1992) and there is certainly some truth in this claim, but it is far less true now than it once was. Hayes, who has perhaps contributed more than anyone to research into ESOL teacher careers (see, e.g., Hayes 
1996, 1997), challenged this view directly in a recent paper based on the life stories of three Sri Lankan teachers (2005). For these teachers the profession is seen as something which, once entered, follows a distinct career path through to retirement. Interestingly, while not suggesting that career progression is unproblematic, Hayes is able to capture through these teachers' voices a sense of remarkably uncomplaining commitment, sustained enthusiasm and undiminished energy late into the career in the face of sometimes extreme threats, including physical violence and political upheaval.

Some also claim that the concept of a career change model is unduly restrictive. While still broadly accepted by many researchers, it has been criticised as failing to reflect the complex and idiosyncratic nature of individual career trajectories (e.g. Cheung 2005). This seems to us to misunderstand the purpose of such models, which are intended not as pigeon-holes but as thematic characterisations in terms of which individual experiences might be interpreted. Work in this area must be distinguished from research into life stories, which needs to be much more richly contextualised and demands a different interpretive stance. Simon-Maeda's study (2004) of the construction of professional identities of female EFL teachers in Japan, for example, probes deeply into personal experiences in order to shed light on the conflictual dynamics of personal and professional engagement with wider institutional and sociocultural forces. The issues of marginalisation and discrimination that it raises have not only general relevance but personal potency.

While the career trajectory highlights aspects of change, it is also important not to exaggerate differences among teachers, however varied their backgrounds and experience. In an illuminating and fascinating investigation into the distinctive characteristics of foreign language teachers, Borg (2006) reveals some interesting features. One of the strengths of his study lies in the range of its sample, which covered five

distinct groups representing over 200 respondents: teachers on a postgraduate TESOL course, language teacher conference delegates, university teachers of other subjects, Hungarian preservice teachers of English, and Slovene undergraduates in English. The picture that emerges is of a dynamic subject, unique in scope and complexity and with a more diverse teaching methodology than other subjects. Particularly interesting is the fact that language teachers, though they are subject to greater commercial pressures than other subject teachers, place particular value on creativity, flexibility and enthusiasm.

The model used here, then, is a convenient organising device, a useful heuristic rather than as a binding interpretive frame, and our decision to include the voice of the individual teacher as discussant recognises the importance of the link between the interpreted world and the lived world, where the qualities identified by Borg are particularly salient. It is almost certainly true that no teacher reading this book will see in it an exact reflection of their own experiences, but neither should they find anything here alien to those experiences, nor anything in the treatment of teacher knowledge that underestimates the complexities of professional engagement.

\section{Teacher knowledge}

Central to this book is the consideration not only of what teachers do but also of why they do it and how this is revealed through their discourses. Perhaps surprisingly, the realisation that 'in order to better understand language teaching we need to know more about language teachers' (Freeman and Richards 1996: 1) is relatively recent (Richards 1994). However, this realisation has led us away from a product-process view of teaching, where teachers are seen to have a body of content knowledge to transmit to students and a set of methodological 
principles with which to do so (Freeman 2002: 4) to the recognition of a complex interrelationship between what teachers know, how they learn and their classroom practice.

According to Tsui (2003: 7) teacher knowledge includes such aspects as knowledge of subject matter, learners, the curriculum, the context in which they work and pedagogy, but she follows Cumming in recognising that the kinds of knowledge teachers draw on in their work 'appear to exist largely in very personalised terms, based on unique experiences, individual conceptions, and their interaction with local contexts' (1989: 46-7, cited in Burns 1992: 57-8).

Such knowledge is context dependent and best seen as developing in a reflexive relationship with the environments in which teachers work. The importance of interaction in the construction of teacher knowledge and understanding has been underlined by Tsui, who notes of the teaching context:

This includes their interactions with people in their contexts of work, where they constantly construct and reconstruct their understandings of their work as teachers.

(Tsui 2003: 64)

Since it is these contexts of work, the interactions that take place there and the consequent construction/reconstruction of teachers' work that are the focus of this book, we now move on to consider the development of teacher knowledge in some of these contexts and in key areas of their professional lives.

\section{Starting out}

At the start of their teaching careers, it may be thought that the most important influence on a new teacher is pre-service teacher education. Yet research has shown that this is often not the case and beginning teachers are often more strongly influenced by their own experiences as learners than by the input from their teacher education programme (Tatto 1998). In particular, pre-service teachers already have strong ideas about teaching as a result of what Lortie (1975) calls 'the apprenticeship of observation', the years spent as pupils observing what it means to be a teacher.

Bailey and colleagues (1996), for example, examined the influence of a teacher's own experience as a learner on how they teach. Their research revealed that ideas about 'good' or 'bad' teaching were strongly influenced by models that teachers were exposed to as learners. Moreover, even in cases where training did seem to have an effect, when faced with difficult situations in the classroom the teachers reverted to teaching in the way they themselves had been taught and not in a way conducive to the learning environment that the training programme wished to encourage. The authors conclude that the 'apprenticeship of observation' is very important in determining how trainees teach and even where new approaches have been learned in teacher training, these do not seem to be available to trainees during difficult moments in the classroom.

An interesting question in initial teacher education concerns the extent to which trainees may pay lip service to what they are taught during their training because they need to pass the course, while their underlying ideas remain basically unchanged. Guttiérez Almarza (1996), for example, notes that while there was evidence that the teacher education programme did play a role in her trainees' practice, the way they talked about this practice was deeply rooted in their pre-training assumptions and experience. 
It would seem, therefore, that it is very difficult for teachers to change deep-rooted and longstanding ideas they have about teaching and learning. Johnson (1994) found that previous formal learning experience was the most powerful influence on teachers' images of themselves as teachers, on their teaching and on their perceptions of their own practices. Even though they were critical of their teacher-centred practices, the teachers in Johnson's study found that they could not change. Any conceptions of alternative practices were based on informal experiences as language learners, but they found that they were unable to translate these experiences into classroom practice.

The above discussion indicates two important aspects of the discursive encounters involved in starting out. First of all, detailed analysis is needed of the discourses of initial teacher education in order to investigate how trainers and trainees construct teacher knowledge, in what areas and how the apprenticeship of observation may act as a filter through which new knowledge is interpreted. Secondly, it is necessary to look at the discourses of post-course experience for evidence of more deep-rooted change that goes beyond conforming to the expectations of the course. This is an area that has been very much neglected in TESOL to date.

\section{Becoming experienced}

As teachers move through their careers, the experiences they gain in the context of their teaching will affect their knowledge and practices. In order to better understand how knowledge develops and evolves as teachers become more experienced, we need to look not only at what teachers do in their day-to-day professional lives but also why they do it. The way in which teachers talk about their experiences is fundamental to understanding how a teacher's knowledge influences what happens in their context of work, and is in turn influenced by what happens there.

Burns (1992) identified three interconnected contextual levels that play a role in the development of the knowledge of experienced teachers. Firstly, there is the institutional level which concerns the "ways in which particular organisational ideologies or philosophies were interpreted by the teachers' (Burns 1992: 158). Secondly there is the classroom level which concerns teacher knowledge and beliefs about language, language learning and the learners themselves. Finally, there is the instructional level which concerns actual lesson planning and decisions made in terms of tasks, materials and the teacher's role. Although models for understanding teachers' classroom decisionmaking have been proposed (e.g. Woods 1996), Burns's contextual levels show that the world of professional experience is much wider. The three levels are presented as distinct, but they are clearly interconnected. Institutional discourses may also impinge on the classroom itself and this is the case of the discourse of the evaluation and assessment of teachers' work, for example. Moreover, what teachers do in their classrooms will have an effect outside as their learners interact in society. This is another neglected area of research in our field which is explored in this collection.

\section{New horizons}

As teachers become increasingly experienced, many feel the need for further professional development. Some may opt for one of the more advanced formal teacher education programmes that are available; others may decide to stay in their classrooms while looking 
for alternative forms of professional development; still others may decide to move out of their classrooms altogether and take on a different role within the profession. Some may do all three.

For those who decide to undertake more a more formal course, there is a question as to the extent to which teacher education influences teacher knowledge beyond just acquiring the discourse. Freeman (1991), for example, looked at how experienced foreign language teachers' conceptions of their practice evolved as a result of the development of a shared professional discourse that emerged during a teacher education programme. He found that as a result of being able to better articulate their thinking using the shared discourse, the teachers gained greater control over their classroom practice. However, the question remains open as to whether the shared discourse simply enabled the teachers to 'make the tacit explicit' (to use Freeman's words), that is, the conceptions they articulated already existed before the training programme, or whether it was participation in the training programme that led to the formation of these conceptions. Freeman concludes that both processes were actually 'taking place simultaneously and interactively' so that there seems to be a dialectical relationship 'in which familiar and tacit knowledge interacts with - and is shaped by - newly explicit understandings' (1991: 453). Today the development of shared discourses is no longer limited to formal teacher education. Advances in information technology mean that experienced teachers from all over the world can now share and support each other in their professional development in ways such as those described by Quirke in this volume. It seems likely that this will give rise to new discourses and shape teacher knowledge in new ways as teachers are able to interact more easily with their peers rather than have to seek knowledge in a formal context. Although research into this area is still very much in its infancy, the importance of analysing these new discourses is clear.

\section{Passing on the knowledge}

As we enter the final stage in the career trajectory outlined in this book, there is a sense in which we have come full circle. The discourses of teachers who pass on the knowledge will shape the beliefs and ideas of those who are just starting out. However, there is another sense in which the cyclenever closes as the knowledge base (Verloop, Van Driel and Meijer 2001) of even the most experienced teachers continues to be shaped by such encounters, both formal and informal, spoken and written.

Those who have written the chapters in this book have passed through all the stages in the career trajectory outlined here. The very act of writing a chapter is to participate in the discourse of passing on the knowledge. But it is equally important that the voices of those who are at different stages of the career cycle are also heard as only they can tell us how relevant the professional encounters that we have described are to them. This is why we have invited practising teachers to offer their reflections and share their experiences in terms of the particular stage of the career cycle that is relevant to them. Those who are reading or working with this book thus have the opportunity to respond not only to the meta-perspective of those who have contributed chapters, but also to the insider views of those who are experiencing the encounters in the here and now.

The world of professional experience in TESOL is vast and in this collection we seek to make connections with a variety of contexts in which decision-making and knowledge construction are realised through discursive encounters. In the final analysis, it is what teachers do in the classroom that counts, but Heraclitus's observation that it is impossible to step into the same river twice might easily be extended to the classroom. The development of the teaching 
experience over 40 or more years, from initial encounters to mature engagement, is subject to a myriad of influences that make the career trajectory - and the knowledges associated with it - a fascinating object of study.

\section{Conclusion}

Although this collection can be read as it stands, working through the career trajectory in its natural temporal sequence, at least one other approach suggests itself. Readers can begin with the section related to their current career stage, reflecting on its relevance or otherwise to their present situation and comparing their views with those of the teacher-reviewer included here. Previous and subsequent career stages can then be explored, so that by relating this 'now' to both perceived past and possible future, readers can explore their current situation and plans from fresh perspectives.

There is a sense in which we build our careers retrospectively, interpreting all that has gone before in terms of a coherent narrative developing to the point we have now reached, producing an ordered progression of tidy events and clear decisions. We hope that this collection will offer a more nuanced perspective and that its contribution will lie not so much in any general claims it might make as in the power of the particular to resonate and to stimulate change:

The powerful moment, the moving insight (though sometimes just from one person or even a handful) is sometimes enough to create dynamic involvement in those who have access to it.

(Schubert 1990: 100)

\section{References}

Bailey, K. C., Bergthold, B., Braunstein, B., Jagodzinski Fleischman, N., Holbrook, M. P., Tuman, J., Waissbluth, X. and Zambo, L. J. 1996. 'The language learner's autobiography: Examining the "apprenticeship of observation"'. In D. Freeman and J. C. Richards (eds), Teacher Learning in Language Teaching. Cambridge: Cambridge University Press, pp. 11-29.

Borg, S. 2006. 'The distinctive characteristics of foreign language teachers'. Language Teaching Research, 10(1): 3-31.

Burns, A. 1992. 'Teacher beliefs and their influence on classroom practice. Prospect, 7(3): $56-66$.

Canagarajah, S. (ed.) 2005. Reclaiming the Local in Language Policy and Practice. Mahwah, NJ: Lawrence Erlbaum.

Cheung, E. 2005. 'Hong Kong secondary schoolteachers' understanding of their careers'. Teachers and Teaching: Theory and Practice, 11(2): 127-49.

Crookes, G. 1997. 'What influences what and how second and foreign language teachers teach?' The Modern Language Journal, 81(1): 67-79.

Cumming, A. 1989. 'Student teachers' conceptions of curriculum: Towards an understanding of language teacher development', TESL Canada Journal, 7(1): 33-51.

Cutting, J. 2000. Analysing the Language of Discourse Communities. Amsterdam: Elsevier. 
Day, C., Stobart, G., Simmons, P. and Kington, A. 2006. 'Variations in the work and lives of teachers: Relative and relational effectiveness'. Teachers and Teaching: Theory and Practice, 12(2): 169-92.

Doyle, W. 1986. 'Classroom organization and management'. In M. C. Wittrock (ed.), A Handbook of Research on Teaching (3rd edn). New York: Macmillan, pp. 392-431.

Fessler, R. and Christensen, J. 1992. The Teacher Career Cycle: Understanding and Guiding the Professional Development of Teachers. Boston, MA : Allyn \& Bacon.

Freeman, D. 1991. "To make the tacit explicit": Teacher education, emerging discourse, and conceptions of teaching'. Teaching and Teacher Education, 7(5/6): 439-54.

Freeman, D. 1992. 'Language teacher education, emerging discourse, and change in classroom practice. In J. Flowerdew, M. Brock and S. Hsia (eds), Perspectives in Second Language Teacher Education. Hong Kong: City Polytechnic of Hong Kong, pp. 1-21

Freeman, D. 2002. 'The hidden side of the work: Teacher knowledge and learning to teach', Language Learning, 35, 1-13.

Freeman, D. and J. C. Richards (eds), 1996. Teacher Learning in Language Teaching. Cambridge: Cambridge University Press.

Gutiérrez Almarza, G. 1996. 'Student foreign language teacher's knowledge growth'. In D. Freeman and J. C. Richards (eds), pp. 50-78.

Hayes, D. 1996. 'Prioritizing "voice" over "vision": Reaffirming the centrality of the teacher in ESOL research'. System, 24(2): 173-86.

Hayes, D. 1997. 'Articulating the context: IN SET and teachers' lives'. In D. Hayes (ed.), Inservice Teacher Development: International Perspectives. Hemel Hempstead: Prentice Hall, pp. 74-85.

Hayes, D. 2005. 'Exploring the lives of non-native speaking English educators in Sri Lanka'. Teachers and Teaching: Theory and Practice, 11(2): 169-94.

Holliday, A. 1994. Appropriate Methodology and Social Context. Cambridge: Cambridge University Press.

Holliday, A. 2005. The Struggle to Teach English as an International Language. Oxford: Oxford University Press.

Huberman, M. 1988. 'Teacher careers and school improvement'. Journal of Curriculum Studies, 20(2): 119-32.

Huberman, M. 1992. 'Teacher development and instructional mastery'. In A. H argreaves and M. G. Fullan (eds), Understanding Teacher Development. London: Cassell, pp. 122-42.

Johnson, K. E. 1994. 'The emerging beliefs and instructional practices of preservice English as a Second Language teachers'. Teaching and Teacher Education, 10(4): 439-52.

Johnston, B. 1997. 'Do EFL teachers have careers?' TESOL Quarterly, 31(4): 681-712.

Lortie, D. 1975. Schoolteacher: A Sociological Study. Chicago: University of Chicago Press.

Maley, A. 1992. 'An open letter to "the profession"”. ELT Journal, 46(1): 96-9.

Pennycook, A. 1994. The Cultural Politics of English as an International Language. London: Longman.

Richards, K. 1994. 'From guessing what teachers think to finding out what teachers know: The need for a research agenda'. TESOL Quarterly, 28(2): 401-4.

Schubert, W. H. 1990. 'Acknowledging teachers' experiential knowledge: Reports from the teacher lore project'. Kappa Delta Pi Record, Summer, 99-100.

Sikes, P. J., Measor, L. and Woods, P. 1985. Teacher Careers: Crises and Continuities. London: Falmer Press.

Simon-Maeda, A. 2004. 'The complex construction of professional identities: Female EFL educators in Japan speak out'. TESOL Quarterly, 38(3): 405-36.

Tatto M. T. 1998. 'The influence of teacher education on teachers' beliefs about purposes of education, roles and practice'. Journal of Teacher Education, 49(1): 66-77. 